\title{
Levels and Determinants of Fine Particulate Matter and Carbon Monoxide in Kitchens Using Biomass and Non-Biomass Fuel for Cooking
}

\author{
Zafar Fatmi ${ }^{1,2}\left(\right.$, Georgia Ntani ${ }^{2}$ and David Coggon ${ }^{2, *}$ (D) \\ 1 Department of Community Health Sciences, Aga Khan University, PO Box 3500, Karachi 74800, Pakistan; \\ zafar.fatmi@aku.edu \\ 2 MRC Lifecourse Epidemiology Unit, University of Southampton, Southampton SO16 6YD, UK; \\ gn@mrc.soton.ac.uk \\ * Correspondence: dnmc@mrc.soton.ac.uk; Tel.: +44-2380-777624
}

Received: 4 January 2020; Accepted: 11 February 2020; Published: 17 February 2020

\begin{abstract}
To assist interpretation of a study in rural Pakistan on the use of biomass for cooking and the risk of coronary heart disease, we continuously monitored airborne concentrations of fine particulate matter $\left(\mathrm{PM}_{2.5}\right)$ and carbon monoxide (CO) for up to $48 \mathrm{~h}$ in the kitchens of households randomly selected from the parent study. Satisfactory data on $\mathrm{PM}_{2.5}$ and $\mathrm{CO}$ respectively were obtained for 16 and 17 households using biomass, and 19 and 17 using natural gas. Linear regression analysis indicated that in comparison with kitchens using natural gas, daily average $\mathrm{PM}_{2.5}$ concentrations were substantially higher in kitchens that used biomass in either a chimney stove (mean difference 611, $95 \%$ CI: $359,863 \mu \mathrm{g} / \mathrm{m}^{3}$ ) or traditional three-stone stove (mean difference 389, 95\% CI: 231, $548 \mu \mathrm{g} / \mathrm{m}^{3}$ ). Daily average concentrations of $\mathrm{CO}$ were significantly increased when biomass was used in a traditional stove (mean difference from natural gas 3.7, 95\% CI: 0.8, $6.7 \mathrm{ppm}$ ), but not when it was used in a chimney stove (mean difference $-0.8,95 \% \mathrm{CI}:-4.8,3.2 \mathrm{ppm}$ ). Any impact of smoking by household members was smaller than that of using biomass, and not clearly discernible. In the population studied, cooking with biomass as compared with natural gas should serve as a good proxy for higher personal exposure to $\mathrm{PM}_{2.5}$.
\end{abstract}

Keywords: biomass; natural gas; particulate matter; carbon monoxide; kitchen; monitoring

\section{Introduction}

Household air pollution from the use of solid fuel (biomass and coal) for cooking or heating has been estimated to cause more than 3.5 million premature deaths per year globally [1,2]. As well as causing respiratory disease and lung cancer [3-5], it has been linked with an increased risk of coronary heart disease, although evidence on the latter is less conclusive [6].

Particularly high exposures may occur among women in developing countries who cook on open stoves burning biomass fuels. However, measured concentrations of the two most frequently studied pollutants (particulate matter with aerodynamic diameter $<2.5$ microns $\left(\mathrm{PM}_{2.5}\right)$ and carbon monoxide (CO)) in cooking areas have varied widely [7,8]. Levels of $\mathrm{PM}_{2.5}$ have generally been from 200 to $1000 \mu \mathrm{g} / \mathrm{m}^{3}$, although at the extremes, values $<10 \mu \mathrm{g} / \mathrm{m}^{3}$ and $>5000 \mu \mathrm{g} / \mathrm{m}^{3}$ have been reported [8]. Measured concentrations of $\mathrm{CO}$ have ranged from $<1$ to $>30 \mathrm{ppm}$ [8]. Possible reasons for the heterogeneity include differences in stove design, room configuration and ventilation, and the presence of other sources of pollution such as environmental tobacco smoke.

In Pakistan, where biomass fuels (mainly wood and cow dung) are used for cooking by some $75 \%$ of households in rural areas [9], we have conducted a series of studies to explore possible effects 
on coronary heart disease in women $[10,11]$. To inform interpretation of those studies, we wished to compare the concentrations of indicator pollutants in kitchens where biomass was used with those in kitchens that used natural gas (a cleaner fuel), and to investigate other factors that might impact on levels of pollution such as the design of the kitchen and stove, and whether there were smokers in the household. To this end, we monitored pollution levels in a random subset of the households that took part in one of the studies of cardiovascular morbidity [11].

\section{Materials and Methods}

The parent study, which had a cross-sectional design, was conducted in villages surrounding the main urban area of Nawabshah district (recently renamed as Shaheed Benazirabad) in the province of Sindh. As described in more detail elsewhere [11], households were recruited through door-to-door visits, to obtain quotas that currently used biomass and natural gas for cooking (Figure 1). We measured $\mathrm{PM}_{2.5}$ and/or $\mathrm{CO}$ in random subsets of 20 households that used biomass and 19 that used natural gas.

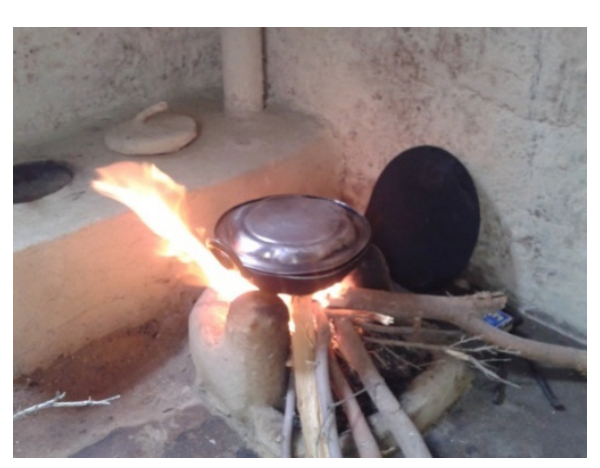

(a) Traditional stove using biomass

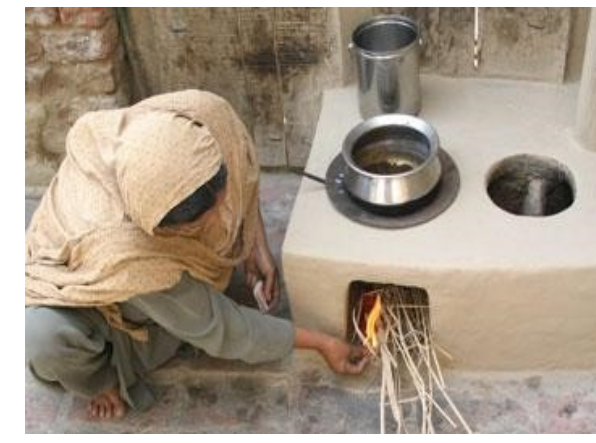

(b) Improved stove using biomass

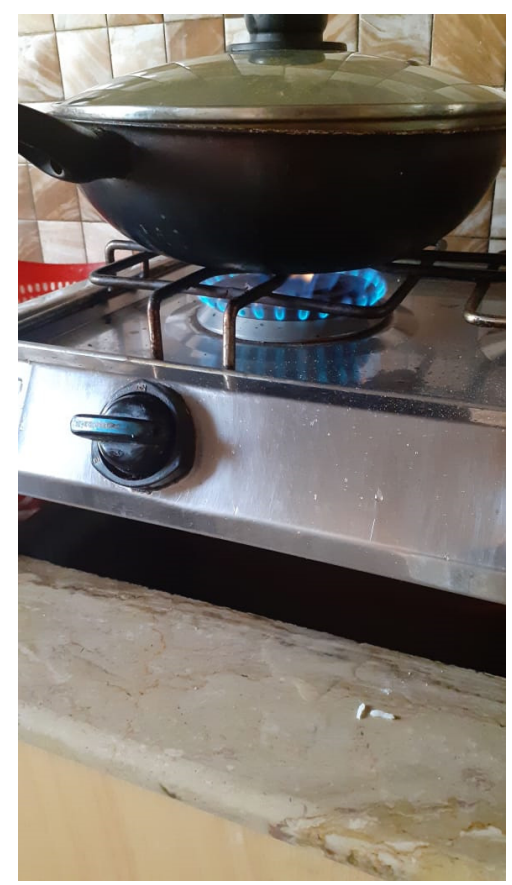

(c) LPG stove

Figure 1. Methods of cooking in the study population.

\subsection{Methods of Measurement}

With agreement from the head of the household, fixed site monitors for $\mathrm{PM}_{2.5}$ and $\mathrm{CO}$ were co-located at a height of approximately one meter (corresponding to the breathing zone of a seated 
person), approximately one meter from the stove or main fire that was used for cooking. The monitors were attached to a wall or suspended from the ceiling, or where that was not possible, placed on a chair or stool. Care was taken not to site them directly downwind or upwind of the stove/fire.

$\mathrm{PM}_{2.5}$ was measured using a single MicroPEM version 3.2 instrument. The device, which was developed by RTI (Research Triangle Institute) International, is lightweight ( $240 \mathrm{~g})$, portable, and powered by AC mains electricity, but can also operate for $24 \mathrm{~h}$ on three AA batteries. Air is sampled through a size-selective inlet that excludes larger particles, and $\mathrm{PM}_{2.5}$ is measured with a light-scattering laser photometer, which gives real-time aerosol mass readings. There is also an integrated facility for parallel collection of particulate matter on a filter for gravimetric analysis. In tests conducted outdoors in Durham, North Carolina, over a period during which levels of $\mathrm{PM}_{2.5}$ were in the order of 4-33 $\mu \mathrm{g} / \mathrm{m}^{3}$, the instrument performed well in comparisons with a Grimm Model EDM180 $\mathrm{PM}_{2.5}$ monitor, taken as a reference [12].

For our study, we carried out 48-h continuous monitoring with logging of data at ten second intervals. Where necessary, batteries were replaced every $24 \mathrm{~h}$. All measurements were made before the monitor was due for the first annual recalibration that was recommended by the manufacturer. We also collected ten 48-h parallel samples for gravimetric analysis, but these proved unsatisfactory because filters were inadvertently contaminated. Thus, it was not possible to calibrate the instrument specifically for local particulate matter.

Static monitoring of CO was carried out with a single Q-RAE (version II) monitor over the same 48-h periods, data being logged at thirty-second intervals. The Q-RAE is a small battery-operated device, which weighs about $500 \mathrm{gm}$ and uses an active pump. $\mathrm{CO}$ is monitored continuously with an electrochemical sensor, which also responds to several other gases, including hydrogen, ethylene, isobutylene, trichloroethylene, and to a lesser extent, ammonia, hydrogen sulphide, propane, and hexane (cross-sensitivities have been reported for 20 common toxic gases [13]). To increase specificity, the instrument has an in-built oxidizing chemical filter that is designed to remove hydrogen sulphide, and a charcoal (carbon) filter that eliminates most other cross-sensitivities. The oxidizing filter is effective for two years, while under normal operating conditions, the carbon filter needs replacement every 4-6 weeks. However, in our investigation, we used a new carbon filter for each household (i.e., replacement after $\leq 48 \mathrm{~h}$ of measurement), since there was a possibility of exposure to relatively high concentrations of pollutants.

Field workers were trained in the use of the sampling equipment, and a detailed manual with pictorial aids was developed to assist them. In each household, monitoring for $\mathrm{PM}_{2.5}$ and $\mathrm{CO}$ started at around $10 \mathrm{am}$. Data were downloaded directly from the MicroPEM and Q-RAE monitors into csv format Excel spreadsheets and text files, respectively.

\subsection{Determinants of Exposure}

Information was noted by the fieldworkers regarding potential determinants of the two pollutants $\left(\mathrm{PM}_{2.5}\right.$ and $\mathrm{CO}$ ), including the type of fuel (biomass or natural gas), stove (three-stone open traditional stove, improved stove, or gas stove), and kitchen (open or semi-open/closed). In addition, information about smoking in the household was obtained through a questionnaire completed by the woman who cooked in the house (with help from the field worker).

\subsection{Statistical Analysis}

All measurements were collated in two datasets, one for $\mathrm{PM}_{2.5}$ and one for $\mathrm{CO}$. After exclusion of those with missing or clearly erroneous values, and correction to zero of those with small negative values (thought to result from minor errors in calibration), arithmetic mean values for each pollutant were derived for each unique combination of household, day, hour, and minute (for $\mathrm{PM}_{2.5}$, a mean of up to six logged measurements in the minute, and for $\mathrm{CO}$, a mean of up to two logged measurements). From these minute by minute values, hourly arithmetic mean concentrations were then calculated, 
together with a count of the number of minutes on which each hourly mean was based. In order to ensure that the hourly means were robust, only those based on 45 or more minutes were retained.

Next, for each household, average concentrations were calculated for each of the $24 \mathrm{~h}$ of the day (taking an average from the two days for which measurements had been made if the data were available). Average daily concentrations were then calculated as the means of these hourly average concentrations for households with data on a sufficient number of hours. For two households in which data on $\mathrm{PM}_{2.5}$ were missing for only one and two hours respectively, the missing values were imputed using the average value for the relevant time of day in other households with the same type of fuel, and the ratio of average measured concentrations across the other hours of the day to that for all other households using the same fuel. Similar imputation was applied for three households with missing data on $\mathrm{CO}$ for one or two hours.

Descriptive statistics were derived for the distributions of hourly mean concentrations in households using biomass and natural gas, and for each type of fuel the average hourly concentration across households was plotted against the time of day.

The relationship between the daily average concentrations of $\mathrm{PM}_{2.5}$ and $\mathrm{CO}$ across households was examined in a scatter plot, and summarized by a Spearman rank correlation coefficient (rho).

Finally, determinants of daily average fixed site concentrations of $\mathrm{PM}_{2.5}$ and $\mathrm{CO}$ were explored by multivariate linear regression.

\subsection{Ethical Considerations}

Written informed consent for the installation of fixed site monitoring devices was obtained from the head of each household. The results were shared with the participants, and if they wished, they were advised about possible modifications that might reduce exposures to pollutants at no or minimal cost. The Ethics Review Committee of Aga Khan University approved the study (reference 3119-CHS-ERC-14).

\section{Results}

\subsection{Completeness of Data}

Measurements of both $\mathrm{PM}_{2.5}$ and $\mathrm{CO}$ were obtained from 18 kitchens using biomass and 19 using natural gas. In addition, $\mathrm{CO}$ measurements were made in two further kitchens that used biomass, where for operational reasons it was not possible to monitor $\mathrm{PM}_{2.5}$.

The total number of measurements for $\mathrm{PM}_{2.5}$ across all households was 744,192 and that for CO 196,618. However, 78,055 measurements of $\mathrm{PM}_{2.5}$ were discarded because of clear measurement error (values either missing or $<-10 \mu \mathrm{g} / \mathrm{m}^{3}$ ). Among the remaining records $(n=666,137)$, those with marginally negative values from -10 to $-1 \mu \mathrm{g} / \mathrm{m}^{3}$, which could plausibly have arisen from minor calibration errors, were set to zero $(n=127,275)$. All measurements of CO were plausible, and none was discarded or amended.

Means were derived for 1826 distinct combinations of household, day, hour, and minute for $\mathrm{PM}_{2.5}$, and 1686 for CO. From these, hourly mean values by household were obtained for $859 \mathrm{~h}$ for $\mathrm{PM}_{2.5}$ and $866 \mathrm{~h}$ for $\mathrm{CO}$. However, 19 hourly means for $\mathrm{PM}_{2.5}$ and 55 for $\mathrm{CO}$ were discarded because measurements were available for $<45 \mathrm{~min}$ in the hour.

Daily average $\mathrm{PM}_{2.5}$ concentrations could not be calculated for two households (one with hourly average concentrations for only $10 \mathrm{~h}$ and the other for $12 \mathrm{~h}$ ). Daily averages for CO were missing for five households, which had hourly averages for $17 \mathrm{~h}$ or fewer.

Final analysis was therefore based on 35 households for $\mathrm{PM}_{2.5}$ (16 using biomass and 19 natural gas) and 34 households for CO (17 using biomass and 17 natural gas; Table 1). Thirty one households contributed data on both pollutants. 
Table 1. Completeness of data.

\begin{tabular}{lll}
\hline Households monitored & $\mathbf{P M}_{2.5}$ & CO \\
\hline Using biomass & 18 & 20 \\
Using natural Gas & 19 & 19 \\
\hline $\begin{array}{l}\text { Number of measurements across all households } \\
\text { Total }\end{array}$ & 744,192 & 196,618 \\
$\begin{array}{l}\text { Discarded because of clear measurement error } \\
\text { Retained }\end{array}$ & 78,055 & 0 \\
\hline Combinations of household, day, hour, and minute for which mean & & 1966,137 \\
concentrations were derived & 1826 & 1686 \\
\hline $\begin{array}{l}\text { Hours for which hourly mean values by household were derived } \\
\text { Total }\end{array}$ & 859 & 866 \\
$\begin{array}{l}\text { Discarded because measurements available for }<45 \text { min in the hour } \\
\text { Retained }\end{array}$ & 19 & 55 \\
\hline $\begin{array}{l}\text { Daily Average Concentrations could not be derived because data } \\
\text { missing for }>\mathbf{2} \text { h }\end{array}$ & 840 & 811 \\
\hline $\begin{array}{l}\text { Daily average concentrations derived and used in analysis } \\
\text { Households using biomass }\end{array}$ & 2 & 5 \\
\hline Households using natural gas & 16 & 17 \\
\hline
\end{tabular}

* Includes 127,275 marginally negative values corrected to zero.

\subsection{Distribution of Measurements}

Hourly mean concentrations of $\mathrm{PM}_{2.5}$ and $\mathrm{CO}$ in kitchens using biomass were substantially higher than in those using natural gas (Table 2).

Table 2. Distribution of hourly mean concentrations of $\mathrm{PM}_{2.5}$ and $\mathrm{CO}$ in kitchens of households using biomass and natural gas for cooking.

\begin{tabular}{ccccc}
\hline & \multicolumn{2}{c}{$\mathbf{P M}_{\mathbf{2 . 5}}\left(\boldsymbol{\mu g} / \mathbf{m}^{\mathbf{3}}\right)$} & \multicolumn{2}{c}{$\mathbf{C O}(\mathbf{p p m})$} \\
\cline { 2 - 5 } & Biomass & Natural Gas & Biomass & Natural Gas \\
\hline Mean & 531 & 69.9 & 6.1 & 3.4 \\
Minimum & 4.2 & 4.2 & 0 & 0 \\
Maximum & 4930 & 2580 & 92.0 & 35.5 \\
Median & 136 & 24.2 & 0.8 & 0.6 \\
25th percentile & 34 & 13.5 & 0 & 0 \\
75th percentile & 615 & 53.3 & 6.4 & 4.9 \\
90th percentile & 1650 & 147 & 16.0 & 11.2 \\
\hline
\end{tabular}

In kitchens where biomass was used, the mean of the hourly mean $\mathrm{PM}_{2.5}$ concentrations was $531 \mu \mathrm{g} / \mathrm{m}^{3}$ with a median of $136 \mu \mathrm{g} / \mathrm{m}^{3}$. The corresponding values for kitchens where natural gas was used were much lower at 69.9 and $24.2 \mu \mathrm{g} / \mathrm{m}^{3}$. For CO, the mean of the hourly mean concentrations in kitchens using biomass was almost twice that in those using natural gas (6.1 vs. 3.4 ppm). However, differences between the median values were smaller ( 0.8 vs. $0.6 \mathrm{ppm})$.

Mean hourly average concentrations by time of the day, calculated separately for households using biomass and natural gas, are presented in Figure $2 \mathrm{a}$ for $\mathrm{PM}_{2.5}$ and Figure $2 \mathrm{~b}$ for $\mathrm{CO}$. In households using biomass, the highest concentrations of both pollutants were in the evening, with smaller peaks in the morning. In households using natural gas, a similar pattern was apparent for $\mathrm{CO}$, although levels tended to be lower than in kitchens where biomass was used. In contrast, mean hourly average concentrations of $\mathrm{PM}_{2.5}$ showed no clear peaks, and were below $180 \mu \mathrm{g} / \mathrm{m}^{3}$ throughout the day. 


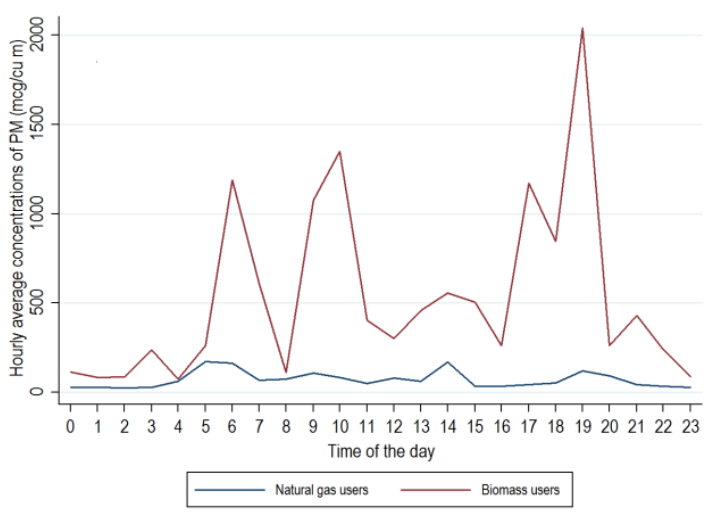

(a)

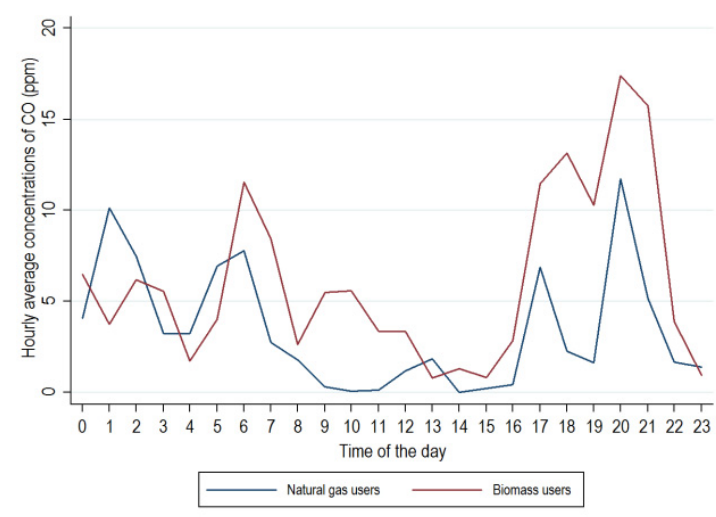

(b)

Figure 2. Arithmetic means across households of hourly average concentrations of (a) $\mathrm{PM}_{2.5}\left(\mu \mathrm{g} / \mathrm{m}^{3}\right)$ and (b) CO (ppm) by time of day and type of fuel.

Daily average concentrations of $\mathrm{PM}_{2.5}$ ranged from 59 to $875 \mu \mathrm{g} / \mathrm{m}^{3}$ in households using biomass and from 25 to $172 \mu \mathrm{g} / \mathrm{m}^{3}$ in households cooking with natural gas. For $\mathrm{CO}$, the corresponding ranges were 1.1-17.3 ppm for biomass-using households and 2.1-5.8 ppm for those using natural gas. Figure 3 plots daily average concentrations for $\mathrm{CO}$ against those for $\mathrm{PM}_{2.5}$ across the 31 households with data on both pollutants. No correlation was observed, either in households using biomass (rho $=-0.17$, $p=0.6)$ or natural gas (rho $=0.03, p=0.9$ ).

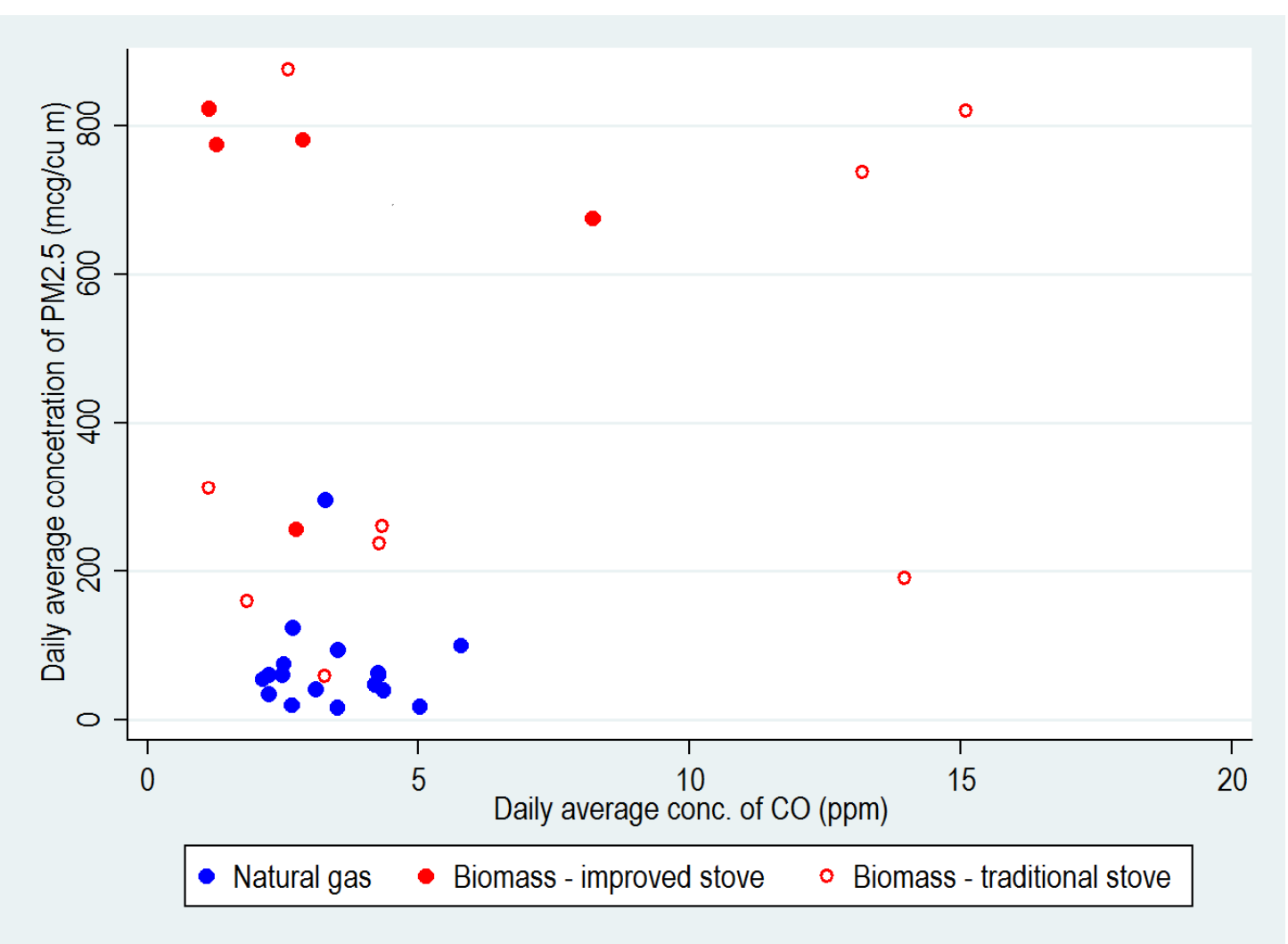

Figure 3. Scatterplot of daily average concentrations of $\mathrm{PM}_{2.5}$ and $\mathrm{CO}$ in households using biomass and natural gas for cooking (based on 31 households with satisfactory data on both pollutants). 


\subsection{Determinants of Daily Average Concentrations of $P M_{2.5}$ and $C O$}

Table 3 presents results from multivariate linear regression analyses relating daily average concentrations of $\mathrm{PM}_{2.5}$ and $\mathrm{CO}$ to type of fuel and stove (natural gas stove vs. biomass used with a chimney stove vs. biomass used with a traditional stove), ventilation of the kitchen (closed/semi-open vs. open) and whether there was one or more smoker in the household (environmental tobacco smoke). Effect estimates for the above factors and their 95\% confidence intervals (CIs) were mutually adjusted in each of two models, one for $\mathrm{PM}_{2.5}$ and one for $\mathrm{CO}$.

Table 3. Mutually adjusted multivariate linear regression coefficients for factors that might influence $\mathrm{PM}_{2.5}$ and $\mathrm{CO}$ concentrations in kitchens. Analysis is based on 35 households for $\mathrm{PM}_{2.5}$ and 34 for CO.

\begin{tabular}{lllll}
\hline Risk Factor & \multicolumn{2}{l}{$\begin{array}{l}\text { Mean Difference in Daily Average PM } \\
\text { Concentration with } \mathbf{9 5 \%} \mathbf{C I}\left(\mu \mathrm{g} / \mathbf{m}^{3}\right)\end{array}$} & $\begin{array}{l}\text { Mean Difference in Daily Average CO } \\
\text { Concentration with 95\% CI (ppm) }\end{array}$ \\
\hline Natural gas stove & Reference & Reference & $(-4.8,3.2)$ \\
\hline $\begin{array}{l}\text { Biomass with } \\
\text { chimney stove }\end{array}$ & 611 & $(359,863)$ & -0.8 & $(0.8,6.7)$ \\
\hline $\begin{array}{l}\text { Biomass with } \\
\text { traditional stove }\end{array}$ & 389 & $(231,548)$ & 3.7 & $(-3.1,4.4)$ \\
\hline $\begin{array}{l}\text { Closed/semi-open } \\
\text { kitchen }\end{array}$ & Reference & Reference & \\
\hline $\begin{array}{l}\text { Open kitchen } \\
\text { Environmental tobacco smoke (ETS) }\end{array}$ & -88.3 & $(-325,148)$ & 0.6 & $(-0.7,5.0)$ \\
\hline No & Reference & & Reference & \\
\hline Yes & 84.5 & $(-65.4,235)$ & 2.1 & \\
\hline
\end{tabular}

In comparison with households using natural gas for cooking, $\mathrm{PM}_{2.5}$ concentrations were significantly higher in those that used biomass, with either a chimney stove (mean difference $611,95 \%$ CI: $359,863 \mu \mathrm{g} / \mathrm{m}^{3}$ ) or traditional three-stone stove (mean difference 389, 95\% CI: $231,548 \mu \mathrm{g} / \mathrm{m}^{3}$ ). Open kitchens tended to have lower $\mathrm{PM}_{2.5}$ concentrations than closed/semi-open kitchens (mean difference $-88.3,95 \% \mathrm{CI}:-325,148 \mu \mathrm{g} / \mathrm{m}^{3}$ ), and smoking in the house was associated with higher $\mathrm{PM}_{2.5}$ levels, although not significantly (mean difference $84.5,95 \%$ CI: $-65.4,235 \mu \mathrm{g} / \mathrm{m}^{3}$ ).

For CO, concentrations were significantly increased with use of biomass in a traditional stove (mean difference from natural gas 3.7, 95\% CI: 0.8, $6.7 \mathrm{ppm}$ ), but not with the use of biomass in a chimney stove (mean difference $-0.8,95 \% \mathrm{CI}:-4.8,3.2 \mathrm{ppm}$ ). Smoking in the house was associated with higher $\mathrm{CO}$, although not to the point of statistical significance. There was no major difference in concentration of $\mathrm{CO}$ according to whether kitchens were open or closed.

\section{Discussion}

Our results indicate that in kitchens using biomass for cooking, average airborne concentrations of $\mathrm{CO}$, and especially $\mathrm{PM}_{2.5}$ were higher than in those using natural gas. Use of a chimney stove appeared to reduce levels of $\mathrm{CO}$, but not of $\mathrm{PM}_{2.5}$. Any effects of smoking on the levels of pollutants were smaller and not clearly discernible.

The average levels of $\mathrm{PM}_{2.5}$ in houses using biomass were some 50-70-fold higher than standards for ambient air in western countries. They are consistent with other studies that have measured $\mathrm{PM}_{2.5}$ in kitchens of biomass-users [8], and indicate a potential for high exposure among women who cook in such kitchens, where they would be expected to spend at least 2-3 h per day, often at times when levels exceeded $1000 \mu \mathrm{g} / \mathrm{m}^{3}$. Concentrations were highest for the longest duration during the evening when most household members, including the women, would be at home.

Levels of $\mathrm{CO}$ were also higher in kitchens using biomass, but unlike $\mathrm{PM}_{2.5}$ were lower when a chimney stove was used. The difference may have contributed to the lack of correlation between daily 
average concentrations of $\mathrm{PM}_{2.5}$ and $\mathrm{CO}$ across kitchens. There were also indications that cooking with gas produced $\mathrm{CO}$ but not $\mathrm{PM}_{2.5}$. Thus, the levels of both pollutants varied substantially by the time of the day in houses using biomass fuel, with two peaks, which most likely corresponded with the main times of cooking. For $\mathrm{CO}$, peaks in concentrations seemed to occur at the same times of the day in the kitchens using natural gas. Previous studies support the possibility that appreciable quantities of $\mathrm{CO}$ are generated when natural gas is used for cooking [14,15].

Use of biomass fuel appeared to be the main determinant of pollutant concentrations in kitchens. Even where biomass was used with a chimney stove, levels of $\mathrm{PM}_{2.5}$ were clearly elevated and similar to those associated with traditional three-stone stoves, whereas $\mathrm{CO}$ concentrations were close to levels in houses using natural gas. This suggests that stoves with a chimney tend to reduce CO but have little influence on $\mathrm{PM}_{2.5}$. Most studies have found that when well-designed standardized chimney stoves were introduced (in intervention trials), they reduced levels of PM and CO [7,16,17], although in one investigation, neither $\mathrm{PM}_{2.5}$ nor $\mathrm{CO}$ was significantly lower in kitchens with homemade chimneys [18]. These apparent inconsistencies may reflect differences in the design of chimneys and levels of ventilation in the kitchens studied, and further research is needed to confirm which designs of chimney are most effective.

Smoking in the household tended to be associated with higher concentrations of $\mathrm{PM}_{2.5}$ and $\mathrm{CO}$, but any effects on levels of the pollutants appeared to be much smaller than those of using biomass for cooking. It was expected that the levels of pollution produced by the burning of biomass fuel would be high compared with those from ETS since few women in the study area were active smokers and any contribution would be mainly from smoking by men, who culturally did not spend much time in kitchens.

No clear reduction in pollutant levels was apparent in open as compared with more closed kitchens. The kitchens in the households studied varied in size, type, construction material and ventilation levels, and the distinction between open and closed kitchens may not always have been clear-cut.

\section{Potential Limitations}

Mainly because of technical problems with equipment, the number of households studied was fewer than planned, which limited the power to compare different types of kitchen, as described above. However, even with the reduced sample size, large differences between fuel types were clearly apparent.

Although households were randomly selected for air monitoring from those participating in the survey of cardiovascular morbidity, the latter were recruited by quota sampling. However, there is no obvious reason why the study sample should have been systematically unrepresentative with regard to differences in pollution levels according to whether solid fuel was used for cooking.

The MicroPEM measures fine particles at concentrations ranging from 1 to $10,000 \mathrm{mg} / \mathrm{m}^{3}$ [19], and performed well when tested against a gravimetric standard [12]. Due to a contamination problem, we were unable to validate our continuous monitoring against gravimetric analysis of samples collected in parallel. Therefore, the absolute values of the $\mathrm{PM}_{2.5}$ measurements may not be fully accurate, and should be interpreted with caution. However, it seems unlikely that measurement error could account for the large diurnal variation in $\mathrm{PM}_{2.5}$ concentrations that we observed only in kitchens using biomass, or the much larger differences in pollution levels that were associated with use of biomass than with type of kitchen or smoking in the household.

The main limitation of the QRAE monitor was the possibility of cross-sensitivity to other gaseous pollutants. The instrument was designed to minimize this problem, but the possibility remains that measurements were somewhat inflated by other pollutants, and this may have contributed to the absence of correlation between daily average concentrations of $\mathrm{CO}$ and $\mathrm{PM}_{2.5}$.

Some measurements were missing because of equipment failure and temporary problems with electrical supply. However, analyses were based only on households with sufficient measurements to characterize exposure levels reliably. 
When the study team visited households to install monitoring equipment in the kitchens, they directly observed the type of fuel, type of stove, and type of kitchen. Therefore, the classification of those variables should have been accurate. Smoking in the household was reported by the woman who cooked in the house, and should also have been ascertained fairly accurately.

\section{Conclusions}

Our study found substantially higher average concentrations of $\mathrm{CO}$ and particularly $\mathrm{PM}_{2.5}$ in the kitchens of biomass-users, which is consistent with other studies. Ventilated kitchens tended to have somewhat lower levels of the pollutants, and houses with smokers somewhat higher concentrations. However, stove chimneys as used in the kitchens studied, had no discernible impact on levels of $\mathrm{PM}_{2.5}$. It follows that within that population, the type of fuel used for cooking can be considered a good index of potential for substantially higher personal exposures to the pollutant among women who cook, with the type of stove, type of kitchen, and smoking in the household being less influential.

Author Contributions: Conceptualization, Z.F. and D.C.; methodology, Z.F. and D.C.; formal analysis, Z.F. and G.N.; data curation, Z.F. and G.N.; writing-original draft preparation, Z.F.; writing-review and editing, Z.F., G.N. and D.C.; supervision, D.C.; project administration, Z.F.; funding acquisition, Z.F. All authors have read and agreed to the published version of the manuscript.

Funding: In conducting this research, Z.F. was supported by a $\mathrm{PhD}$ studentship from the Colt Foundation. G.N. and D.C. were supported through a grant from the Medical Research Council (MRC_MC_UU_12011/5).

Acknowledgments: Syed Nayab Ali Shah coordinated the field sampling and measurement. Tanzeel Jamali (deceased) provided technical support for downloading and organizing the data.

Conflicts of Interest: The authors declare no conflict of interest. The funders had no role in the design of the study; in the collection, analyses, or interpretation of data; in the writing of the manuscript, or in the decision to publish the results.

\section{References}

1. Bonjour, S.; Adair-Rohani, H.; Wolf, J.; Bruce, N.G.; Mehta, S.; Prüss-Ustün, A.; Lahiff, M.; Rehfuess, E.A.; Mishra, V.; Smith, K.R. Solid fuel use for household cooking: Country and regional estimates for 1980-2010. Environ. Health Perspect. 2013, 121, 784-790. [CrossRef] [PubMed]

2. World Health Organization. Household Air Pollution and Health. Geneva, Switzerland. Available online: http://www.who.int/mediacentre/factsheets/fs292/en/ (accessed on 28 December 2019).

3. Torres-Duque, C.; Maldonado, D.; Pérez-Padilla, R.; Ezzati, M.; Viegi, G. On behalf of the Forum of International Respiratory Societies (FIRS) Task Force on Health Effects of Biomass Exposure. Biomass fuels and respiratory diseases: A review of the evidence. Proc. Am. Thorac. Soc. 2008, 5, 577-590. [CrossRef] [PubMed]

4. Gordon, S.B.; Bruce, N.G.; Grigg, J.; Hibberd, P.L.; Kurmi, O.P.; Lam, K.B.H.; Mortimer, K.; Asante, K.P.; Balakrishnan, K.; Balmes, J.; et al. Respiratory risks from household air pollution in low and middle income countries. Lancet Respir. Med. 2014, 2, 823-860. [CrossRef]

5. Bruce, N.; Dherani, M.; Liu, R.; Hosgood, H.D.; Sapkota, A.; Smith, K.R.; Straif, K.; Lan, Q.; Pope, D. Does household use of biomass fuel cause lung cancer? A systematic review and evaluation of the evidence for the GBD 2010 study. Thorax 2015, 70, 433-441. [CrossRef] [PubMed]

6. Fatmi, Z.; Coggon, D. Coronary heart disease and household air pollution from use of solid fuel: A systematic review. Br. Med. Bull. 2016, 118, 91-109. [CrossRef] [PubMed]

7. Clark, M.L.; Peel, J.L.; Balakrishnan, K.; Breysse, P.N.; Chillrud, S.N.; Naeher, L.P.; Rodes, C.E.; Vette, A.F.; Balbus, J.M. Health and household air pollution from solid fuel use: The need for improved exposure assessment. Environ. Health Perspect. 2013, 121, 1120-1128. [CrossRef] [PubMed]

8. Carter, E.; Norris, C.; Dionisio, K.L.; Balakrishnan, K.; Checkley, W.; Clark, M.L.; Ghosh, S.; Jack, D.W.; Kinney, P.L.; Marshall, J.D.; et al. Assessing exposure to household air pollution: A systematic review and pooled analysis of carbon monoxide as a surrogate measure of particulate matter. Environ. Health Perspect. 2017, 125, 076002. [CrossRef] [PubMed] 
9. Pakistan Demographic and Health Survey 2017-2018; National Institute of Population Studies: Islamabad, Pakistan, 2018; Available online: https://datacatalog.worldbank.org/dataset/pakistan-demographic-andhealth-survey-2017-2018 (accessed on 13 February 2020).

10. Fatmi, Z.; Coggon, D.; Kazi, A.; Naeem, I.; Kadir, M.M.; Sathiakumar, N. Solid fuel use is a major risk factor for acute coronary syndromes among rural women: A matched case control study. Public Health 2014, 128, 77-82. [CrossRef] [PubMed]

11. Fatmi, Z.; Ntani, G.; Coggon, D. Coronary Heart Disease, hypertension and use of biomass fuel among women: Comparative cross-sectional study. BMJ Open 2019, 9, e030881. [CrossRef] [PubMed]

12. Williams, R.; Kaufman, A.; Hanley, T.; Rice, J.; Garvey, S. Evaluation of Field-Deployed Low Cost PM Sensors; EPA/600/R-14/464 (NTIS PB 2015-102104); U.S. Environmental Protection Agency: Washington, DC, USA, 2014. Available online: https://cfpub.epa.gov/si/si_public_record_report.cfm?Lab=NERL\&dirEntryId=297517 (accessed on 28 December 2019).

13. RAE Systems, Honeywell. TN-114: Sensor Specifications and Cross-Sensitivities. Available online: http://www.raesystems.com/customer-care/resource-center/tn-114-sensor-specifications-and-crosssensitivities (accessed on 10 October 2019).

14. Mullen, N.A.; Li, J.; Russell, M.L.; Spears, M.; Less, B.D.; Singer, B.C. Results of the California Healthy Homes Indoor Air Quality Study of 2011-2013: Impact of natural gas appliances on air pollutant concentrations. Indoor Air 2016, 26, 231-245. [CrossRef] [PubMed]

15. Siddiqui, A.R.; Lee, K.; Bennett, D.; Yang, X.; Brown, K.H.; Bhutta, Z.A.; Gold, E.B. Indoor carbon monoxide and PM2.5 concentrations by cooking fuels in Pakistan. Indoor Air 2009, 19, 75-82. [CrossRef] [PubMed]

16. Smith, K.R.; McCracken, J.P.; Thompson, L.; Edwards, R.; Shields, K.N.; Canuz, E.; Bruce, N. Personal child and mother carbon monoxide exposures and kitchen levels: Methods and results from a randomized trial of woodfired chimney cookstoves in Guatemala (RESPIRE). J. Exp. Sci. Environ. Epidemiol. 2010, 20, 406-416. [CrossRef] [PubMed]

17. McCracken, J.; Smith, K.R.; Stone, P.; Diaz, A.; Arana, B.; Schwartz, J. Intervention to lower household wood smoke exposure in Guatemala reduces ST-segment depression on electrocardiograms. Environ. Health Perspect. 2011, 119, 1562-1568. [CrossRef] [PubMed]

18. Pollard, S.L.; Williams, D.L.; Breysse, P.N.; Baron, P.A.; Grajeda, L.M.; Gilman, R.H.; Miranda, J.J.; Checkley, W.I. CRONICAS Cohort Study Group. A cross-sectional study of determinants of indoor environmental exposures in households with and without chronic exposure to biomass fuel smoke. Environ. Health 2014, 13, 21. [CrossRef] [PubMed]

19. Research Triangle Institute (RTI). Available online: https://www.rti.org/sites/default/files/brochures/rti_ micropem.pdf (accessed on 29 December 2019). 